\title{
Laparoscopic management of gastric cancer
}

The development of minimally invasive surgery following the first cholecystec-

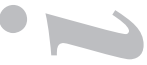
tomy performed nearly 20 years ago has favored the performance of increasingly aggressive procedures to reduce surgical trauma and improve quality of life during the postoperative period of time $(1,2)$. The management of gastric cancer could not escape this trend, and various minimally invasive technical options have been currently described - early-stage endoscopic mucosal resection, partial resection with limited lymphadenectomy, and in recent years laparoscopy-assisted or fully laparoscopic partial or total gastric resection (3-11). However, no definite evidence is yet available on both their short-term and long-term clinical advantages as compared to open surgery, but we are obtaining increasingly more information in support of the potential benefits of such an approach (2), particularly that these procedures are oncologically appropriate -as suggested in the study by Ibáñez et al. (10)- both from a technical perspective and considering their long-term effects.

The two main goals of gastric cancer management are prolonged survival and improved quality of life (12). It is widely accepted that surgical treatment is crucial in the therapeutic approach to gastric cancer, albeit no universal consensus has been reached regarding the specific procedure. This stems from the fact that surgery outcomes are better in Asia than in the West, where Asian-like results could not be reproduced. This has resulted in serious controversy, and some Western authors wonder whether these are distinct conditions with differing behaviours, whether patients are of a different type, and - from a surgical standpoint - which lymphadenectomy is oncologically most appropriate or which gastrointestinal reconstruction should be performed (13).

Disease is probably the same in both the East and West, but Asian series indeed report patients with earlier stages and fewer comorbidities, whereas in Europe or the U.S. gastric cancer is diagnosed in more advanced stages, which confers a poorer prognosis (12).

From a technical point of view there is no consensus regarding lymphadenectomy extent. While Asian teams support more extensive lymphadenectomies (D2 or D3), most Western groups prefer a more limited D1 dissection entailing a milder postoperative morbidity and lower mortality (12). The reasons for such differences stem from the fact that Japanese groups have reported better outcomes with extensive lymphadenectomy, whereas such results could not be reproduced in Europe or the U.S. (12,13). Thus, randomized studies performed in Europe by Cuschieri and Bonenkamp to compare D1 to D2 lymphadenectomy found that survival was not longer with the D2 approach, while patients treated this latter way did have greater morbidity and mortality (14-16).

The possibility of treating gastric cancer laparoscopically adds a new dilemma to those existing: is it possible to reproduce using laparoscopy the same technique as 
performed in open surgery and then obtain the same results? Fifteen years ago, in the early days of laparoscopic surgery, not even surgeons most enthusiastic about this technique could believe that gastric cancer was to be currently managed through this approach, basically due to its technical complexity and concerns regarding the feasibility of an oncologically acceptable lymphadenectomy. However, several factors have allowed that this concept be changed, and that laparoscopic gastrectomy for gastric cancer be presently a fact -on the one hand the progression of laparoscopic learning in gastric surgery, already initiated with submucosal or partial resections in benign conditions or stromal tumors; on the other hand, the development of instruments and laparoscopic materials that facilitate advanced laparoscopic procedures (harmonic scalpel, optical improvements, etc.). In addition, one should bear in mind results from prospective, randomized studies performed for the study of laporoscopic approach efficacy in colon cancer, which have demonstrated the benefits of laparoscopic colectomy in particular, and the safety of the laparoscopic approach to gastrointestinal cancer in general (2). All this is apparent in the series presented by Ibáñez (10), which shows in the first place an adequate technical competence for any technique required by gastric cancer surgery (partial/total gastrectomy, lymphadenectomy), as well as long-term results, with none of the feared adverse effects of laparoscopy in cancer (implants in trocars) being identified despite the greater biological aggressiveness of gastric cancer.

Laparoscopic surgery in gastric cancer was launched by Asian groups who reported good results in the treatment of early-stage mucosal lesions, with a faster postoperative recovery and equal oncologic efficacy $(3,4)$. Some studies have been subsequently reported showing good results in stage-II/III tumors with subtotal or total gastrectomies fully performed through laparoscopy or under laparoscopic assistance, with lymphadenectomies that oncologically matched those performed with open surgery, and obviously a morbidity and mortality that were also similar $(5,6)$.

Few randomized studies compare laparoscopic subtotal gastrectomy to open gastrectomy. Lee, in 47 patients with early cancer, found a milder surgical trauma, less respiratory capacity reduction, fewer hospitalizations, lower pain levels, and faster postoperative recovery in the laparoscopic group (7). Of late, Hayashi (8) obtained similar results in 28 patients also with early cancer: less intraoperative blood loss, reduced analgesic requirements, a faster return of gastrointestinal function, and fewer hospitalizations in the laparoscopic group. Regarding oncologic efficacy, he saw no differences in the number of resected adenopathies, and no local relapses or trocar metastases occurred (8).

Huscher, in the only European randomized study comparing laparoscopic subtotal gastrectomy versus open gastrectomy with D2 lymphadenectomy in stage II/III gastric tumors, confirms the radicality of laparoscopic resection when he finds no differences in survival and disease-free individuals at 5 years between both groups. In addition, as in other laparoscopic procedures, he finds advantages such as smaller blood loss, a faster return to oral ingestion, and shorter hospital stays (9).

Unfortunately, laparoscopic gastrectomy cannot be considered yet a new surgical gold standard as of today. We expect that, in the near future, long-term randomized studies will define the real usefulness of gastric cancer laparoscopic management regarding postoperative morbidity and mortality, and oncologic effectiveness. Also, as Ibáñez (10) reports in his paper, these studies will elucidate the true impact of this technique on quality of life and overall financial costs. Thence we shall establish the real contribution of the laparoscopic approach in the management of gastric cancer. However, as of today, we may certainly state that laparoscopic gastrectomy for gas- 
tric cancer is a safe, reproducible technique when carried out by laparoscopy-experienced surgeons in appropriately selected patients. Therefore, it is an alternative to open surgery provided that we can accurately use the same tenets applicable to open surgery in the laparoscopic approach.

E. M. Targarona, X. Feliu ${ }^{1}$ and C. Balagué

Service of Surgery. Hospital de Sant Pau. Universidad Autónoma de Barcelona ${ }^{1}$ Hospital de Igualada. Igualada, Barcelona. Spain

\section{REFERENCES}

1. Feliu X, Targarona EM, García Agustí A, Pey A, Carrillo A, Lacy AM, et al. The developement of laparoscopic surgery in Spain. Dig Surg 2004; 21: 421-5.

2. Peschaud F, Alves A, Berdah S, Kianmanesh R, Laurent C, Mabrut JY, et al.; French Society of Digestive Surgery. Indications of laparoscopic general and digestive surgery. Evidence based guidelines of the French society of digestive surgery. Ann Chir 2006; 131: 125-48.

3. Adachi Y, Shiraishi N, Shiromizu A, Bandoh T, Aramaki M, Kitano S. Laparoscopy-assisted Billroth I gastrectomy compared with conventional open gastrectomy. Arch Surg 2000; 135: 806-10.

4. Kitano S, Iso Y, Moriyama M, Sugimachi K, Bandoh T, Aramaki M, et al. Laparoscopy-assisted Billroth I gastrectomy. Surg Laparosc Endosc 1994; 4: 146-8.

5. Huscher CG, Mingoli A, Sgarzini G, Sansonetti A, Lirici M, Napolitano C, et al. Videolaparoscopic total and subtotal gastrectomy with extended lymph node dissection for gastric cancer. Am J Surg 2004; 188: 728-35.

6. Tanimura S, Higashino M, Fukunaga Y, Osugi H. Laparoscopic distal gastrectomy with regional lymph node dissection for gastric cancer. Surg Endosc 2003; 17: 758-62.

7. Lee JH, Han HS, Lee JH. A prospective randomized study comparing open vs. laparoscopy-assisted distal gastrectomy in early gastric cancer. Surg Endosc 2005; 19: 168-73.

8. Hayashi H, Ochiai T, Shimada H, Gunji Y. Prospective randomized study of open vs. laparoscopy-assisted distal gastrectomy with extraperigastric lymph node dissection for early gastric cancer. Surg Endosc 2005; 19; $1172-6$.

9. Huscher CG, Mingoli A, Sgarzini G, Sansonetti A, Di Paola M, Recher A, et al. Laparoscopic versus open subtotal gastrectomy for distal gastric cancer. Five-year results of a randomized prospective trial. Ann Surg 2005; 241: 232-7.

10. Ibáñez Aguirre FJ, Azagra JS, Erro Azcárate ML, Georgen M, Rico Selas P, Moreno Elola-Olaso A, et al. Laparoscopic gastrectomy for gatric adenocarcinoma. Long-term results. Rev Esp Enferm Dig 2006; 98 (7): 491-500.

11. Lee SI, Choi YS, Park Do J, Kim HH, Yang HK, Kim MC. Comparative study of laparoscopy-assisted distal gastrectomy and open distal gastrectomy. J Am Coll Surg 2006; 202: 874-80.

12. Dicken BJ, Bigam DI, Cass C, Mackey JR, Joy AA, Hamilton SM. Gastric adenocarcinoma. Review and considerations for future directions. Ann Surg 2005; 241: 27-39.

13. Griffin SM. Gastric cancer in the East: same disease, different patient. Br J Surg 2005; 92: 1055-6.

14. Fédération Nacionale des Centres de Lutte contre le Cancer. Standards, options et recomendations pour la prise en charge des patients atteints d'adenocarcinomes de l'estomac. Available at: http://www.fnclcc.fr/sor.htm. 2004

15. Cuschieri A, Weeden S, Fielding J, Bancewicz J, Craven J, Joypaul V, et al. Patient survival after D1 and D2 resections for gastric cancer: long-term results of the MRC randomised surgical trial. Br J Cancer 1999; 152230.

16. Bonenkamp JJ, Hermans J, Sasako M, van de Velde CJ, Welvaart K, Songun I, et al.; Dutch Gastric Cancer Group. Extended lymph-node dissection for gastric cancer. N Engl J Med 1999; 340: 908-14. 